\title{
Opioids and pain in the emergency department: a narrative crisis
}

\author{
Jay Baruch, ${ }^{1}$ Stacey Springs ${ }^{2}$
}

\begin{abstract}
The opioid crisis poses challenges to patients who come to the emergency department (ED) in pain and the clinicians who have a duty to offer relief. In search of help, patients often find suspicion. But clinicians have reasons to be concerned about feeding addiction and its lethal consequences. This article discusses the narrative challenges facing many clinicians in the ED tasked with caring for complex patients in pain. It will discuss the many ways our brains are influenced by story, and how this susceptibility is often beyond our grasp. And yet, narrative and story skills present great opportunities for improving pain management, not only when it comes to opioids, but by returning the focus back to the patient in pain.
\end{abstract}

Janelle $\mathrm{M}$ is a young woman in a sickle cell crisis who came to the emergency department (ED) with unbearable pain in her joints. Now she is laughing and chatting on her cellphone. When she is asked to rate her pain on a 1-10 pain scale, she says it is a 10 , a number that represents the worst imaginable pain. When she first arrived in the ED her pain was a 10, only at that time she appeared to be in obvious distress. She received medications for her pain, including a dose of opioids. Her sickle cell is generally well managed as an outpatient. Now, the ED staff cannot square her pain level with her pain behaviour, opening the door to suspicion that sickle cell disease might not be her only problem, the other concern being for an opioid use disorder (OUD).

In the ED there are two major obstacles to understanding, appreciating and responding to patients complaining of pain. The first pertains to pain's subjectivity. Elaine Scarry said it best. 'To have pain is to have certainty, to hear about pain is to have doubt.'

${ }^{1}$ Department of Emergency Medicine, Alpert Medical School at Brown University, Providence, Rhode Island, USA

${ }^{2}$ Center for Evidence Synthesis in Health, Brown University School of Public Health, Providence, Rhode Island, USA

Correspondence to Dr Jay Baruch, Department of Emergency Medicine, Alpert Medical School at Brown University, Providence, RI 02905, USA; jay_baruch@brown.edu
The other belongs to the long shadow of the opioid crisis ravaging communities in the USA, where opioid deaths have quadrupled over the past three decades. Data from the Centers for Disease Control and Prevention (CDC) show that four out of five heroin users began their habit by using prescription opioids, though these data have been contested. ${ }^{2}$ Between 2005 and 2014 the national rate of opioid-related ED visits increased 99.4\%, with a 10 -fold variability across states. ${ }^{3}$

Systemic responses to this public health crisis have included recommendations from the CDC laying out responsible prescribing guidelines for patients suffering from chronic pain, making naloxone, the opioid-reversal agent, more readily available in our communities, and even starting medication-assisted treatment for OUD in the ED. ${ }^{4}$ These valuable policies and programmes take aim at necessary and measurable outcomes: reduce the number of opioids on the streets, keep patients alive and move individuals into treatment for their OUD.

These robust and justifiable interventional strategies must be carried out cautiously. The vigilant quest to curb opioid overdose and misuse may seed clouds of suspicion that alters how clinicians come to recognise and appreciate pain. This change in status, from a complicated and often distressing experience to a red flag, can produce a paradox in emergency pain management where pain is unaddressed and potentially made worse.

When pain is reported to be the most common complaint that drives patients to the ED, accounting for up to $70 \%$ of visits, ${ }^{5}$ clinicians are challenged to honour their fundamental duty to ameliorate pain and suffering while respecting the potential morbidity and mortality associated with opioid abuse and misuse. This endeavour is difficult in ways that are unlike other medical situations that clinicians encounter. Guidelines are important to direct pain management practice patterns, but before clinicians make the decision to use the guidelines and perhaps prescribe opioids they will listen to the stories patients tell them.

Pain is a narrative challenge as well as a medical one, and narrative plays an instrumental role in how clinicians understand and respond to our patients at the bedside. The mind does not just receive what is told, it is a story-making machine, and the stories it creates present opportunities for understanding and misunderstanding patients.

\section{PAIN IS NOT A NUMBER}

Pain cannot be plucked from its roots, located on a CT scan or quantified by a lab test. And yet its presence is real to patients who desperately seek relief from it, whatever that 'it' is.

Pain has been broadly defined as an 'unpleasant sensory and emotional experience associated with actual or potential tissue damage, or described in terms of such damage. ${ }^{6}$ This dutiful and well-intentioned definition leaves a dull, medicinal taste on the tongue. It succeeds by acknowledging the emotional as well as the sensory dimensions of pain while demonstrating how pain can be elusive yet undeniable, escaping the most conscientious efforts to capture the experience into words.

The physician/writer David Biro wrote achingly about pain as a quintessentially private experience, how 'pain of any variety isolates us from our family and closest friends. No one could feel what I felt during my transplant-not my wife or my parents or my sisters. And the inability to find words for my feelings only exacerbated my loneliness."7

In The Body in Pain, Elaine Scarry describes how pain is in essence inexpressible. Not only does pain resist language, it destroys it, reverting back to the 'sounds and cries a human being makes before language is learned.' ${ }^{1}$

Pain's subjectivity and inexpressibility, even by writers who possess the gift of language, point to the difficult task facing patients who struggle to articulate their experience in the busy ED, where patients are usually telling their story to clinicians who know little or nothing about them.

One might say that Janelle $M$ endures chronic pain with her lifetime of sickle cell crisis flares. For patients in the throes of pain, however, all pain is acute. The ED might not be the ideal location to treat chronic pain, however, patients often find their way to this acute care setting for their care. ${ }^{8} 9$ Patients do not necessarily like coming to the ED, but due to the severity of their pain, they believe they are experiencing a true emergency. Once in the ED setting, these patients often feel frustrated, helpless and unable to 'communicate effectively' with clinicians. ${ }^{10}$ 
Deciphering a patient's pain can test clinicians who are more comfortable caring for patients whose complaints can be recognised through objective measures-vital signs, physical exam findings, laboratory tests or radiological imaging - and treatment is informed by appealing to evidence-based medicine.

In the late 1990s, medicine was mired in a different public health crisis-the undertreatment of pain. In 2001, the Joint Commission unveiled Pain Management Standards that established the fantastical notion of pain as a fifth vital sign. ${ }^{11}$ Pain scales were instituted, and patients' self-reports of their pain were to be aggressively treated by physicians, often with opioids. Equally fascinating is how the recent pushback against such quality measures is largely in response to the belief that such expectations fuelled overprescribing and possibly contributed to the opioid crisis, and not that policymakers woke up to the inherent folly of translating a subjective experience into a data point.

The case of Janelle M illustrates how a number may earn more validity than it deserves from providers, and what happens when clinicians, consciously or not, seek solace in false certainty.

Many, if not most, emergency physicians can recall patients who declare their pain to be a 10 and yet their pain behaviour does not match up. There is no crying or moaning or writhing on the stretcher. This disconnect invariably leads to judgement of the patient. Instead, this gap should prompt a critique of pain scales and how clinicians use them to find traction in experiences that might be difficult to understand otherwise.

Assigning a number to pain does not only compress a complex experience, it can falsely shorthand the experience. In the end, Janelle $M$ was not asking for more opioids. Her pain was severe but tolerable.

Any number on a pain scale presents a calibration problem. What constitutes a 10 ? How does Janelle M's 10 match up against that of another patient? A number serves as a proxy representation of a personal experience but it should not be confused for the pain itself.

A laughing patient with 10 out of 10 pain prompts suspicion for illicit motives. However, Janelle M explains how, over the years, she has developed a coping mechanism using laughing and distraction. She talks with friends and family to make her pain bearable. Janelle M's story probably cannot be extrapolated to all comfortable-looking patients with 10 out of 10 pain. However, her experience offers a window into one patient's experience and highlights how clinicians may fall prey to the stories they have constructed about a patient.

This case illustrates another deleterious consequence of using numbers without insight. Instead of doubting a patient who had developed more holistic and adaptive behaviours to deal with her pain, we should be applauding this alternative, non-narcotic strategy in an opioid crisis.

\section{PAIN, A STORY PROBLEM}

Arthur Frank wrote that stories always pose this question: What kind of truth is being told? Stories do not always resolve that question, but they serve to remind us that we live with complicated truths. ${ }^{12}$ Stories are rich with possibilities. Stories explore not only what characters do but they probe the motivations behind their behaviour; do not only describe what is, but what could be. ${ }^{12}$

The clinician's response to a patient's pain often depends on what story they are looking for. Strangely, in an opioid crisis, it feels as if the question of whether or not to prescribe an opioid is a more straightforward question to answer than the challenge of coming to grips with a patient's pain, which can be a tangled ball of problems and often leaves clinicians struggling with uncertainty. ${ }^{13}$

In his book, The Culture of Pain, David Morris states that to be in pain is to be in a state of crisis. Modern medicine, with a Western, technocratic world view, misrepresents pain as purely a medical problem, the creation of anatomy and physiology, and ignores the experience of pain as phenomena of the mind, shaped by historical, cultural and psychosocial factors. ${ }^{14}$

In an opioid crisis, it can be hard for clinicians to think of the experience of pain as a crisis, too. It is easier to simplify the experience rather than amplify it. Paradoxically, the pain history that is a staple of the medical interview and documented as such in the medical record can represent a thorough accounting and an empty one. The clinician takes a descriptive inventory of the pain. Pain is described with a bank of adjectives, such as throbbing, burning, aching or knife-like. Pain is quantified as mild, moderate or severe. Pain is mapped as it radiates and moves through time. These objectifying questions use various dimensions of the pain to help diagnose an underlying cause of the pain. The sudden onset of left-sided chest pressure that radiates to the shoulders might signify a heart attack. A thunderclap headache can mean a subarachnoid haemorrhage in the brain.
Pain has instrumental value when considered in these terms.

These factual elements build a frame around the pain but omit pain's impact on the patient's life. Pain can influence relationships, job performance and the ability to think and reflect clearly. Pain can chip away at a patient's identity and autonomy, influencing his or her ability to function in the present, and their capacity to conceive of a future. Pain can be an everlasting struggle to make it through the day. A story is not a rich list of symptoms, but the process of endowing an experience with meaning. ${ }^{15}$

Mary $\mathrm{J}$ is a young woman who comes to the ED in the middle of the night with a recurrence of her chronic back pain. She has suffered from back pain ever since a bad car crash when she was a teenager. Her physical exam does not reveal any red flags that might raise concern for a vertebral fracture, nerve root impingement or an infection of the spinal cord. She rates her pain as a 4 or 5 . She comes to the ED and she has not tried anything to relieve her pain at home, not even acetaminophen. And at its worst, her pain is only a 5 . The physician is suspicious. That evening he has already cared for a few patients seeking opioids, whose medical records and prescription monitoring database revealed illicit behaviours. The physician informs her that back pain is best treated with non-opioid treatments. ${ }^{16}$

A wounded disappointment sinks her face. She does not want opioids. She explains that she is a new mom and her pain gets worse when she lifts her infant. She has acetaminophen at home, only she is breast feeding and unsure what medications might hurt her baby. She is here now, in the middle of the night, and not visiting her clinic during the day, because they only have one car, her boyfriend leaves for work at 06:00, and she does not trust anyone to watch her baby.

Her calm tone only exacerbates the physician's regret. He manufactured a narrative and filled in the gaps in her story, and that was influenced, in part, by his experiences with more notorious patients that evening. He fit her details into an overarching narrative built around opioids without thinking imaginatively about those details he did not have. Or, his story-making mind jumped to a conclusion and focused only on information that supported that judgement.

Mary J's story reveals a particular and personal form of trouble, which makes her perception of an emergency fascinating. Stories involve a protagonist in trouble, 
someone who wants something badly but faces a series of obstacles. Sometimes pain is the obstacle. Sometimes opioids are the obstacle. It can be easy to confuse pain intensity for the degree that pain, regardless of its severity, alters a patient's life. Mitigating this mistake is possible by considering the patient as the protagonist in her story and exploring her motivations behind her actions or behaviour. If the clinician pursued this type of inquiry he would have learnt earlier that Mary J could live with her pain but she could not live with the possibility of harming her baby.

Framing pain as a narrative problem creates space for the imagination in pain management, in particular, the moral imagination. It is not enough to extend ourselves to consider the possible, all that could happen in a patient's story, without recognising that clinicians owe a responsibility to think about what should happen, and the ways in which they are culpable.

\section{STORY RECEPTORS, AND HOW CLINICIANS CAN GET HOOKED}

Research shows how stories work on the brain. A good story can slip past our analytical neural circuitry, engage with our emotions and influence our decisions without our knowledge.

The tragic opioid data sit in the rational part of my brain. In 2014, there were 245 million prescriptions for opioids across America, roughly one prescription for every adult. ${ }^{17}$ I am painfully aware of the rising trend of opioid deaths. And yet, data struggle to compete against a good story, and clinicians can play many participatory roles in the narrative. A force of compassion or an agent of scepticism, a pain reliever or addiction feeder. Sometimes, clinicians are not even thinking in these terms because they are emotionally invested in the story. Whether the story is believable matters less once the story inserts its hooks.

$\mathrm{Mr} \mathrm{O}$ is a middle-aged man with a long history of pain and other health issues who presents to the ED with terrible pain. Sleep is impossible, and he has job interviews lined up the next 2 days. He has been out of work for a few months, and without health insurance, his regular doctor would not see him. He has been parsing out the remaining pain medications-including opioids-the past few months. Now he is all out. An appointment with a new physician is months away. He is desperate to get back to work, and these interviews are the first glimpses of hope in months.
The nurses doubt his story. The physician has doubts, too, but he empathises with the man's plight, a guy stuck in a hole trying to dig himself out. In the end, he writes a prescription for 10 Lortabs, trade name for a hydrocodone-acetaminophen formulation. Only 10 tablets. The next day there is a message from a local pharmacy. Had he really written a prescription for a hundred? The physician usually spells out the number of pills to prevent this type of alteration. Thankfully, the alert pharmacist suspected a forgery and did not fill the order. The nurses rib the physician mercilessly. How can he be duped so easily?

But what if Mr O's manipulation of the prescription-clearly a criminal activitywas driven by alternative motives? Maybe he saw an opportunity to stock up on pills so he could keep his pain at bay, the aim to function well enough so he can pull his life back together. What if he is selling the pills to pay for other medications, and there is a list of them, many of them carrying a hefty monthly price tag. In the USA, debt related to health expenses is the most common cause of bankruptcy. ${ }^{18}$ These narrative possibilities are unlikely given the data on opioid misuse in ED patients, but data do not engage our emotions in the same way as a good story, even if it is not necessarily true. ${ }^{19}$

Research using functional MRI shows that our brains respond to story-whether it is a movie or a story on the page-as if it is happening to us. In fact, a coupling develops between the speaker and the listener, creating a synchronised neural activity what might be described as a shared brain. ${ }^{20}$ Researchers speculate that 'dialogue will produce especially strong forms of synchronization.' The stronger the connection between the speaker and the listener, the closer the coupling.

Narrative can change minds, and this persuasive power is tied to the neural phenomenon of transportation. People who are swept away by a story and taken to a different world begin to see the world in a manner that is consistent with the story. Whether it is fact or fiction matters less than the quality of the narrative. ${ }^{21}$

A well-told story with a dramatic arc can elicit empathy and influence our behaviour, in part by stimulating the release of the neurochemical oxytocin, which has ties to generosity, trustworthiness and mother-infant bonding. ${ }^{22}$ It alerts us to social cues, motivates us to help others. Such trust and sensitivity to the plight of patients may allow clinicians to lower their guard, which can make them susceptible to deceit. However, welltold stories also hold promise as we strive to understand and connect with patients in pain.

\section{STORIES AS TREATMENT}

When it comes to pain, which ear are clinicians listening with? The ear that is open to the investigation of pain, or the ear that is on the lookout for opioid-seeking behaviour.

Both ears must be recruited for this endeavour. However, patients might not trust clinicians with their story if they feel they are being heard through the sceptic's ear. Patients who might already feel isolated by their pain, troubled by the difficulties of expressing their experiences, might feel pushed further away.

Even when patients do not ask for opioids, there is a good chance clinicians are thinking of opioids. When data illuminate how ordinary people without a history of abuse are at risk for opiate abuse syndrome, even people in legitimate pain are not immune to suspicion from what they might become.

A complete understanding of the perspectives and attitudes of patients concerning their ED experiences for pain highlights a desire for more engagement regarding their treatment plan, more empathy and better communication, and a preference for goals around functional status. Patients are frequently aware of the dangers posed by opioids and recognise the stressful situations clinicians face regarding opioid prescribing. ${ }^{23}$ Patients sometimes decline analgesic pain medications, concerned more with the cause of their pain and what it might mean than the severity of the pain itself. $^{24}$

Patients isolated by their experience of pain can find themselves further adrift in the busy and often chaotic ED, and what patients desire is not necessarily opioids but empathy from providers and recognition of their pain. ${ }^{1023}$ Pain can be particularly difficult to understand when it is an expression of something deeper to access, a state of suffering. Eric Cassel said, 'suffering is a state of severe distress that occurs when the physical or psychological integrity of the person is threatened. It continues until the threat is gone or the integrity restored. 25

Restoring a patient's integrity is a tall order, but honouring their dignity and not shying away from difficult conversations regarding their life with pain is the least that patients should expect. Evidencebased guidelines have been developed with the purpose of educating clinicians about best practices to ensure responsible treatment strategies for pain while discouraging 
opioid abuse and misuse. ${ }^{26-29}$ Other ED strategies include openly declaring to patients that they do not prescribe opioids and instead use non-opioid medications and other treatment modalities like massage, nerve blocks and trigger point injections. ${ }^{30}$ EDs have partnered with state agencies to better coordinate the care of patients suffering from chronic pain. ${ }^{10}$

In addition to these strategies, clinicians must appreciate that effective pain management and responsible opioid stewardship first require a fundamental attention to patient stories. There are psychological comforts of storytelling. Humans have been telling stories for thousands of years, providing humans the impression they have control over the world. But clinicians must be savvy to the power and perils of stories. They can help rearticulate our understanding of the patient's experience but they may also seduce us with its charms. Interestingly, storytelling shows promise as a tool in dampening the opioid crisis by improving the recall and implementation of opioid prescribing guidelines. ${ }^{31}$

Ultimately, story is a medium for connection. It is the equivalent of the child rubbing a boo-boo on a playmate in the sandbox. The power of that gesture is not that rubbing will necessarily offer relief, but that another human being recognises the troubled experience of another and seeks to ameliorate it.

A story of suffering can be profoundly difficult to express and to listen to. Clinicians must be open to that possibility because to miss it, or to ignore it, could serve as an iatrogenic harm even if stateof-the-art guidelines are followed. As Cassel described, suffering is not always the result of the disease but as a result of its treatment. ${ }^{25}$

The paradox of responsible pain management involves finding compassionate ways to curb opioid prescribing while not curbing the clinician's interest in the patient's experience of pain. And if opioids are indeed a problem, thinking about addiction as a narrative to be understood rather than a habit to be judged.

Story can empower patients by making them heroes in their own stories. Clinicians must learn to offer each and every patient an affirmation of their struggles, and recognise how difficult life can be.

The people impacted by the tragedy of the opioid crisis have stories to tell. So do those patients suffering from pain. We need all their stories. We need as many alternative perspectives as possible, stories of how we are all trying to 'hold are own' in our own stories.

How do we become better at crafting the stories of our own lives? Arthur Frank suggests that we recognise how 'many different stories are doing different things for people and to people. ${ }^{, 12}$

It might be hard to change the condition responsible for a patient's pain, but that does not mean clinicians cannot treat their story, and focus on the many ways they are holding their own against difficult circumstances. We inhabit the stories we create and the stories we create influence how we live. Part of our response to patients in an opioid crisis is helping them write a story that they can live with.

Funding The authors have not declared a specific grant for this research from any funding agency in the public, commercial or not-for-profit sectors.

Competing interests None declared.

Patient consent Not required.

Provenance and peer review Not commissioned; externally peer reviewed.

Author note Identifying details of the case have been changed in this paper.

(c) Author(s) (or their employer(s)) 2018. No commercial re-use. See rights and permissions. Published by BMJ.

\section{D) Check for updates}

To cite Baruch J, Springs S. Med Humanit 2018:44:213-216.

Accepted 5 June 2018

Published Online First 26 June 2018

Med Humanit 2018:44:213-216. doi:10.1136/ medhum-2017-011429

\section{REFERENCES}

1 Scarry E. The Body in Pain: The Making and Unmaking of the World: Oxford University Press, 1987.

2 Center for Disease Control and Prevention. Increases in Drug and Opioid Overdose Deaths - United States, 2000-2014. 2016 https://www.cdc.gov/ $\mathrm{mmwr} /$ preview/mmwrhtml/mm6450a3.htm?s_cid= mm6450a3 w.

3 Audrey J, Weiss PD, Elixhauser A. Opioid-Related Inpatient Stays and Emergency Department Visits by State, 2009-2014. 2017 https://www.hcup-us.ahrq. gov/reports/statbriefs/sb219-Opioid-Hospital-Stays-EDVisits-by-State.jsp (accessed December 12 2017).

4 D'Onofrio G, O'Connor PG, Pantalon MV, et al. Emergency department-initiated buprenorphine/ naloxone treatment for opioid dependence: a randomized clinical trial. JAMA 2015;313:1636-44.

5 Cordell WH, Keene KK, Giles BK, et al. The high prevalence of pain in emergency medical care. $\mathrm{Am} \mathrm{J}$ Emerg Med 2002;20:165-9.

6 IASP. IASP Taxonomy. https://www.iasp-pain.org/ Taxonomy (accessed 5 Dec 2017).

7 Biro D. The Language of Pain: Finding Words, Compassion, and Relief: W. New York: W. Norton \& Company, 2010.

8 MacKichan F, Brangan E, Wye L, et al. Why do patients seek primary medical care in emergency departments? An ethnographic exploration of access to general practice. BMJ Open 2017;7:e013816.
9 Marcozzi D, Carr B, Liferidge A, et al. Trends in the Contribution of Emergency Departments to the Provision of Hospital-Associated Health Care in the USA. Int J Health Serv 2018:48.

10 Donovan E, Ranney ML, Reid AM, et al. Chronic Pain in the Emergency Department. R / Med J2017;100:25-9.

11 Fiore K. Opioid Crisis: Scrap Pain as 5th Vital Sign? MedPage 2016.

12 Frank AW. Letting Stories Breathe: A Socio-Narratology Chicago: University of Chicago Press, 2012

13 Simpkin AL, Schwartzstein RM. Tolerating Uncertainty - The Next Medical Revolution? N Engl J Med 2016:375:1713-5.

14 Morris DB. The Culture of Pain: University of California Press, 1993.

15 Bruner J. Actual Minds, Possible Worlds: Harvard University Press, 1987

16 Krebs EE, Gravely A, Nugent S, et al. Effect of Opioid vs Nonopioid Medications on Pain-Related Function in Patients With Chronic Back Pain or Hip or Knee Osteoarthritis Pain: The SPACE Randomized Clinical Trial. JAMA 2018:319:872-82.

17 Volkow ND, McLellan AT. Opioid Abuse in Chronic Pain--Misconceptions and Mitigation Strategies. N Engl J Med 2016;374:1253-63.

18 Henry J. Kaiser Family Foundation. The Burden of Medical Debt: Results from the Kaiser Family Foundation/New York Times Medical Bills Survey. 2016 https://www.kff.org/health-costs/report/theburden-of-medical-debt-results-from-the-kaiser-familyfoundationnew-york-times-medical-bills-survey/view/ print/ (accessed 10 Mar 2018).

19 Logan J, Liu Y, Paulozzi L, et al. Opioid prescribing in emergency departments: the prevalence of potentially inappropriate prescribing and misuse. Med Care 2013;51:646-53.

20 Stephens GJ, Silbert LJ, Hasson U. Speaker-listener neural coupling underlies successful communication. Proc Natl Acad Sci U S A 2010;107:14425-30.

21 Green MC, Brock TC. The role of transportation in the persuasiveness of public narratives. J Pers Soc Psychol 2000;79:701-21.

22 Barraza JA, Alexander V, Beavin LE, et al. The heart of the story: peripheral physiology during narrative exposure predicts charitable giving. Biol Psychol 2015;105:138-43.

23 Smith RJ, Rhodes K, Paciotti B, et al. Patient Perspectives of Acute Pain Management in the Era of the Opioid Epidemic. Ann Emerg Med 2015:66:246-52

24 Green SM. There is oligo-evidence for oligoanalgesia. Ann Emerg Med 2012:60:212-4.

25 Cassel EJ. The nature of suffering and the goals of medicine. N Engl J Med 1982;306:639-45.

26 Dowell D, Haegerich TM, Chou R. CDC Guideline for Prescribing Opioids for Chronic Pain--United States, 2016. JAMA 2016:315:1624-45.

27 Lipp C, Dhaliwal R, Lang E. Analgesia in the emergency department: a GRADE-based evaluation of research evidence and recommendations for practice. Crit Care 2013:17:212

28 Beaudoin FL, Banerjee GN, Mello MJ. State-level and system-level opioid prescribing policies: The impact on provider practices and overdose deaths, a systematic review. J Opioid Manag 2016;12:109-18.

29 Manchikanti L, Abdi S, Atluri S, et al. American Society of Interventional Pain Physicians (ASIPP) guidelines for responsible opioid prescribing in chronic non-cancer pain: Part 2--guidance. Pain Physician 2012;15(3 Suppl):S67-116.

30 Hoffman J, E.R A. kicks the habit of opioids for pain New York Times. 2016 https://www.nytimes.com/ 2016/06/14/health/pain-treatment-er-alternativeopioids.html (accessed 1 Mar 2018).

31 Kilaru AS, Perrone J, Auriemma CL, et al. Evidencebased narratives to improve recall of opioid prescribing guidelines: a randomized experiment. Acad Emerg Med 2014;21:244-9. 